\title{
LIST OF REFEREES
}

The editorial committee wishes to thank the referees.

- Adetoun Adebanjo

Independent Consultant

- Akinola Akintayo

Department of Public Law, Faculty of Law, University of Lagos, Nigeria

- Caroline Authaler

Department of History, Universität Heidelberg, Germany

- Victoria Balogun

School of Law, University of Kwazulu-Natal, South Africa

- Yvette Hutchison

School of Theatre, Performance and Cultural Policy Studies, University of Warwick, United Kingdom

- David Nnanna C. Ikpo

Centre for Human Rights, Faculty of Law, University of Pretoria, South Africa

- Richard Lumbika

Human Rights Center, Kongo University, South Africa

- Sara Matchett

Drama Department, University of Cape Town, South Africa

- Walter Gam Nkwi

Department of History, University of Buea, Cameroon

- Stefaan Smis

Department of International Law, Vrije Universiteit Brussel, Belgium

- Alex Sutherland

Drama Studies, Rhodes University, South Africa

A special thanks to Stéphanie Schaubroeck for helping with the layout of the figures. 